\title{
Chapter 8 \\ The Representation of Human-Environment \\ Interactions in Land Change Research and Modelling
}

\author{
Peter H. Verburg
}

\subsection{Introduction: Land Change and Spatial Models}

Land change is the result of multiple human-environment interactions operating across different scales. Land change research needs to account for processes ranging from global trade of food and energy to the local management of land resources at farm and landscape level. Land change has a pronounced impact on the local and global environment. Land change may cause degradation of the living environment through soil degradation or changes in the aesthetic qualities of the landscape. At the same time, land change may lead to aggregate impacts on larger spatial and temporal scales, examples include the impacts on global climate and food security. Such impacts affect human well-being and often feedback on land use practices and decision making by adapting to the changing environmental and socio-economic context. Human-environment interactions in the land system are, therefore, connected across scales with multiple feedbacks, leading to so-called 'teleconnections' or 'telecoupling' in the earth system. The same process may cause different trajectories of land change in different world regions: globalization of food production can cause deforestation in tropical regions while marginal agricultural landscapes in other regions are abandoned. The local environmental and socio-economic context determines how the same global changes lead to different trajectories of land change in different parts of the world.

Land change occurs at the interface of human and environmental systems and is crucial in understanding both the causes and consequences of global environmental change. Local land change decisions are often made by individual land owners.

P.H. Verburg $(\bowtie)$

Institute for Environmental Studies, VU University Amsterdam,

De Boelelaan 1087, 1081HV Amsterdam, The Netherlands

e-mail: peter.verburg@vu.nl 
In some cases land owners decide on land practices of small agricultural plots in terms of farming practices as well as having the opportunity to sell their land or buy adjacent plots. In other cases land owners have authority to make land use decisions over large areas of land managed by multiple individual farmers. When ownership is linked to the state or community, decision making on land resources is either the outcome of a political process (e.g. in assigning concessions for deforestation) or a result of communal decision making. Irrespective of the land ownership, land change decisions are steered by both the preferences of the land owner and managers and the way in which the decision process is influenced by the environmental conditions, commodity markets, socio-economic context and other driving factors. The spatial and temporal diversity of the actors of land change, the environment and the socioeconomic and cultural context lead to a wide array of different land change trajectories with processes operating across multiple spatial scales. Such diversity expresses itself in a diverse mosaic of land use within the landscape and in the development of widely diverging trajectories of landscape change worldwide.

Effective management of land resources and the transition towards sustainable natural resource management can only be achieved based on a thorough understanding of the complex interactions and feedbacks in the land system. Land science has developed a wide portfolio of methods to investigate land system change, ranging from local case studies aimed at understanding the land change decisions leading to land change to global scale integrated assessment models that evaluate the impacts of land change on the earth system functioning. One of the major challenges of the land change community is to reconcile the different methodological approaches at different scales and make complementary use of the different types of knowledge generated. Computer simulation models play an important role in land science. Models provide a platform for formalized synthesis of the knowledge on the functioning of the land system, allow hypothesis testing and allow the exploration of alternative development trajectories and intervention options. This chapter will review how human-environment interactions are conceptualized in land science and land change models in particular. The chapter will explicitly address how social science knowledge is integrated in land change models and discuss a research agenda for further improving the representation of human agency in land change models.

\subsection{The Representation of Human-Environment Interactions in Land Change Models}

\section{Conceptual models of human-environment interactions in land science}

A theory of land system change should conceptualize the relationships between the driving and conditioning forces and land use change; including the relationships among the driving forces and human behavior and organization underlying these relationships. Existing disciplinary theories can help to analyze aspects of land change in specific situations and under well-defined assumptions. However, the paradigms 
and theories applied by the different disciplines are often difficult to integrate and their specific foci do not easily combine into an integrated understanding of land change. So far researchers have not yet succeeded in defining an all-compassing theory of land change and it can be questioned if the formulation of such theory is within reach. The lack of such overarching theory hampers the design of (conceptual) models to represent the human-environment interactions underlying land change.

Theories from multiple disciplines, such as economics, geography, ecology and anthropology, contribute to the explanation of land change. Often, these theories are related to specific land conversion processes or sectors, e.g. Boserupian theory concerning the effects of population on land use intensity (Boserup 1965; Turner and Fischer-Kowalski 2010; Turner and Ali 1996), neo-Thünen theory about moving frontiers and urban markets (Walker 2004; Walker and Solecki 2004) and the theories of Fujita and Krugman about urban development (Fujita et al. 1999a, b) as notable examples. Most theories cannot adequately explain the complexity of land use decision making underlying the observed land changes. Assumed agent behaviors in the common rational choice paradigm are very restricted and a variety of alternative decision making models are available (Meyfroidt 2012). Rational choice theory may reasonably explain land use decisions under the bid-rent paradigm. However, in reality individuals may rather seek to minimize risks or take them, as the case may be (Rabin 1998). Poorly defined property rights are not conducive to the competitive bidding process that leads to the equilibrium rent profile, which is most frequently underlying urban and agricultural models (Parker and Filatova 2008). In a recent review of the representation of decision making in land change research, Meyfroidt (2012) concludes that in land change science the cognitive aspects of decision making are underrepresented. His overview of alternative decision making models is synthesized by the notion that (i) land use choices result from multiple decisionmaking processes and rely on various motives, influenced by social norms, emotions, beliefs, and values toward the environment; (ii) social-ecological feedbacks are mediated by the environmental cognitions, that is, the perception, interpretation, evaluation of environmental change, and decision-making; (iii) human agents actively re-evaluate their beliefs, values, and functioning to adapt to unexpected environmental changes (Meyfroidt 2012).

The different, alternative, representations of decision making in land change and land change models are discussed by Hersperger et al. (2010) who describe 4 conceptual models that (often implicitly) underlie much land change model representations. Figure 8.1 summarizes the three most important models identified by Hersperger. We have added a fourth model that explicitly addresses the socio-ecological feedbacks and re-evaluation of decision making upon environmental change.

The first model looks for a direct relation between driving factors and land change, e.g. between population and agricultural intensity or between road building and deforestation. The identification of the underlying driving factors of land change has been a popular research topic and many papers have, for specific case studies, revealed the locally most important drivers of land change. Decision making that moderates the relation between driving factors and land change is often implicit and not analyzed explicitly. The relations between driving factors and land change can 


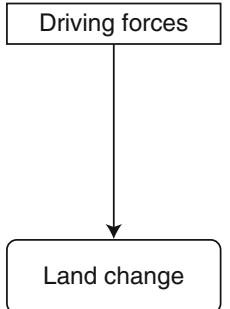

II

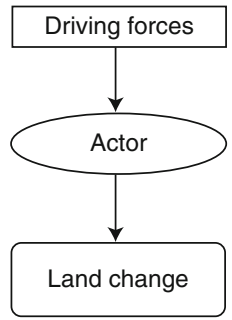

III

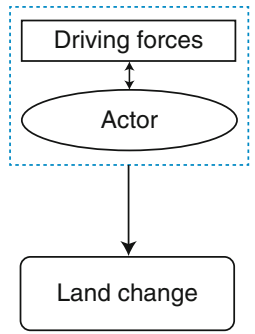

IV

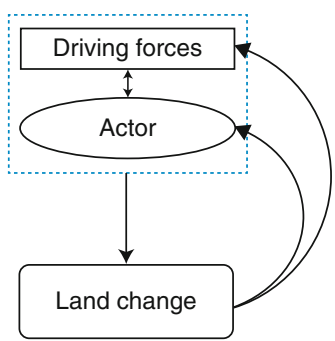

Fig. 8.1 Conceptual models for the representation of the relation between driving factors and land change (Modified after Hersperger et al. 2010)

be established by empirical analysis using observed land change data and statistical techniques, either based on spatial data or household interviews (Bürgi et al. 2004; Verburg et al. 2004a; Walsh et al. 1999). When using spatial data, statistical models are estimated that relate locations of observed land change (as dependent factor) to the spatial distribution of the driving factors (as independent factors). For example, locations of urbanization may be associated with locations of improved accessibility, resulting in a statistical model that relates accessibility to urbanization.

The second model represents the chain from driving factors to actor to land change. Although the actor has an explicit role in this sequence, the decision making of the actors itself may not be studied in detail and uniform decision making structures may be assumed. In addition, the driving factors are assumed to be independent of the actors. Examples of the application of this conceptual model include many economic land change models in which all actors are assumed to behave according to an uniform rational choice model (Happe et al. 2006). In such models the actors are supposed to make decisions based on land rent. Land rent is then explained as a function of driving factors, e.g. soil suitability and transportation costs.

The third conceptual model explicitly addresses the decision making process and accounts for the fact that the same driving factor may lead to a different land change outcome depending on variations in the decision making process. Examples include many social science studies in which variations in decision making between groups of the population are studied. As an example, Overmars et al. (2007) identified that in a case study in the Philippines, different ethnic groups have different land use decision strategies based on cultural tradition and knowledge. In many agent-based land change models a typology of agents is made in which the different groups are represented by different decision making rules towards land change (Valbuena et al. 2008). In the model of Valbuena et al. (2010a) hobby farmers are distinguished from commercial farmers as the decision making of both groups is governed by different objectives and motivations.

The fourth conceptual model, which we have added in addition to the models of Hersperger et al., represents an explicit feedback from land change to the actor and the driving factors. These feedbacks cause an impact of land change on the driving 
factors of land change, or invoke changes in the decision making strategy as result of actor learning, adaptation and perception in response to the experienced land change. Feedbacks between land change and decision making are not always straightforward and direct. Often the feedback operates across different spatial or temporal scales. Local land changes add up to impacts on the global climate system, in turn leading to local impacts in vulnerable regions in terms of changes in cropping conditions or increased flood risks to which people adapt their decision. The importance of such feedbacks was stressed by van Noordwijk et al. (2011) and Meyfroidt (2012). Unfortunately, only a small number of examples of the study of such feedbacks are available in the land science literature, mostly due to the difficulty of observing and quantifying such feedback mechanisms (Claessens et al. 2009; Verburg 2006).

\subsubsection{Different Perspectives and Research Approaches}

To obtain a full understanding of the causes and consequences of land change a complementary use has to be made of different research approaches. These can be classified as the narrative, the empirical and the modeling approaches (Lambin et al. 2003). The results of the narrative and empirical approach are often used as input to the modeling approach that aims at formalizing the identified relations in a structured framework.

The narrative approach seeks depth of understanding through historical detail and interpretation. It tells the land change story, providing an empirical and interpretative baseline by which to assess the validity and accuracy of the other visions. It is especially beneficial in identifying stochastic and random events that significantly affect land change but might be missed in approaches employing less expansive time horizons or temporal sampling procedures (Briassoulis 2000). The narrative approach is mostly valid at the level of individual actors and one of the challenges of the approach is to link it with the features of land change that occur at more aggregate levels of analysis. This has given rise to efforts to better link 'people and pixels' through georeferencing narrative research and efforts to link the narrative approach to empirical approaches using geographical data (Liverman and Cuesta 2008; Rindfuss et al. 2003; Rindfuss and Stern 1998). By linking household data to the spatial units of land managed by those households, it becomes possible to relate household characteristics to the actual land management applied in the field.

The empirical approach builds on the narrative approach but takes a more quantitative perspective by identifying significant relations and pattern in the collected data while testing hypothesis that are either based on the narrative research approach or through deductive reasoning (Pfaff and Sanchez-Azofeifa 2004). Such empirical analysis can take place at various levels of spatial and temporal aggregation, ranging from the analysis of household survey data (Overmars and Verburg 2005) or the analysis of spatial units, i.e. pixels or polygons, organized in geographic data layers (Chomitz and Gray 1996; Veldkamp et al. 2001) to the analysis of time series of 
country-level statistics (Rudel et al. 2009). A major drawback of the empirical quantification of relations between land use and its supposed drivers is the induced uncertainty with respect to the causality of the supposed relations. The danger lies in leaping directly from the exploratory stage, or even from statistical tests based on descriptive models, to conclusions about causes (James and McCulloch 1990). Besides, most causal explanations are valid at the scale of study, mostly the individual actor of land change, and therefore subject to upscaling problems. This asks for validation of the causality of empirically derived relations. A combination of the narrative perspective with the empirical perspective can help to test the validity of the empirical relations. An example of such a combined approach is a study of Overmars in the Philippines (Overmars and Verburg 2005). Overmars used an approach that evaluates the results of statistical models based on geographic data by a household-level analysis of decision making.

The modeling approach uses theoretical, assumed or empirical relations to construct a model that allows the exploration of land change dynamics across historic (observed) or future time periods. Models especially allow the analysis of 'what-if' questions through acting as an artificial laboratory for conducting controlled experiments which are very difficult to establish in the real world. Similarly to the empirical perspective, land change models are aimed at a wide variation of different spatial and temporal scales. Local agent-based models mostly represent individual actors within a community or small region (Matthews et al. 2007) while spatial models often are applied at the regional level, simulating the changes in land use of land units or pixels. Land use is also an explicit part of larger scale models operating at the global level, ranging from global equilibrium models of the world economy (Hertel et al. 2010) to integrated assessment models of global environmental change (Thomson et al. 2010). The following section will describe the way in which human-environment interactions are addressed in land change models in more detail.

From the above it is clear that both the different research approaches and the different spatial scales of analysis are able to provide complementary insights. However, the linking of the approaches across the different scales may not be straightforward. Coleman (1990) developed a framework that describes the interaction between micro and macro levels for social systems. The same framework can also be applied to land change models. Land change assessments made at the regional level, using remote sensing and geographic data, are often explained by specifying a micro-level mechanism. Figure 8.2, based on the work of Coleman (1990), depicts the relations between the macro and micro levels. Macro-level analyses (pathway A) of land use are normally based on empirical techniques, e.g. the analysis of spatial patterns of land use derived from remote sensing. Pathway B explains the underlying processes from which the different land use patterns have emerged, e.g. the individual decisions in response to the (changing) socio-economic and physical context. Aggregated, these individual decisions lead to changes in land use pattern that can be analyzed in the more macro-scale analysis. This aggregation may not be straightforward due to non-linear relationships causing the 'ecological fallacy' or 'modifiable area unit problem' (Easterling 1997; Marceau and Hay 1999). 


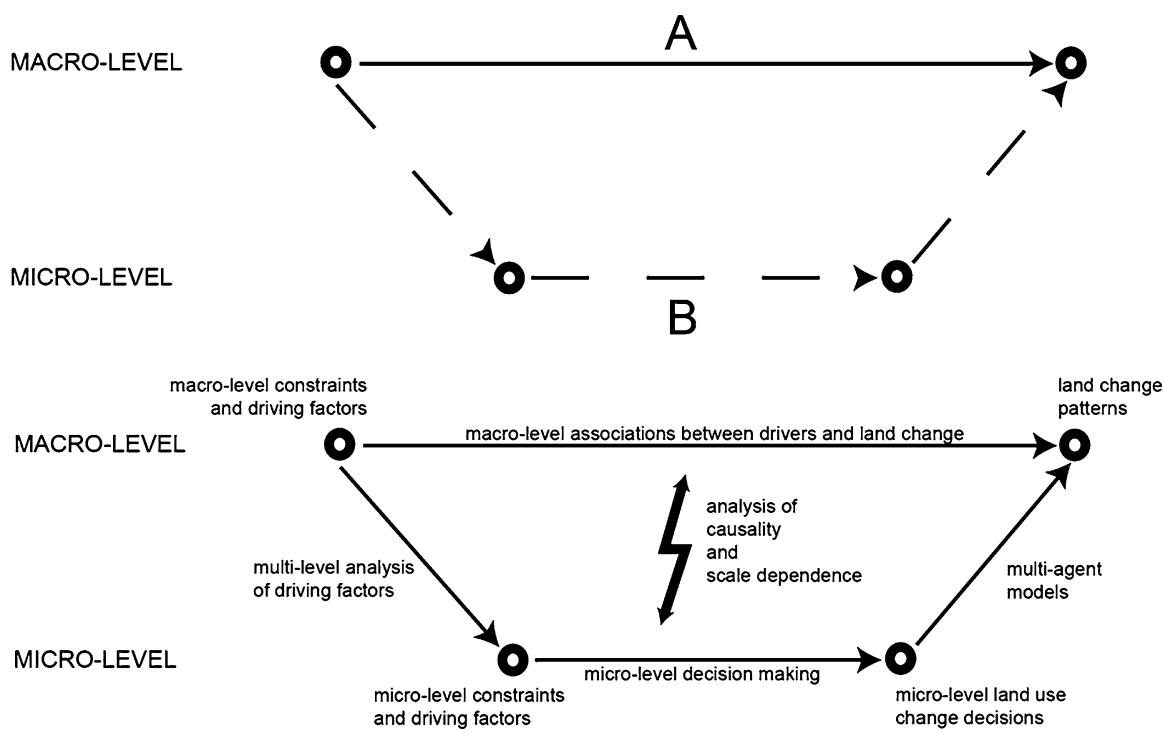

Fig. 8.2 Illustration of the relations between macro and micro-level analysis of land change (Based on Coleman 1990)

These terms relate to the bias that is introduced when non-linear relations at individual level are applied to aggregate data. Also, interactions between agents, e.g. leading to collective behavior, as well as the role of institutions and other 'collective' agents lead to aggregate results that deviate from the sum of individual decisions (Gibson et al. 2000; Liu et al. 2007). Tools have been developed to analyze the role of processes across multiple scales, e.g. multi-level statistics (Neumann et al. 2011; Overmars and Verburg 2006; Pan and Bilsborrow 2005) and agent-based models, that model the emergence of patterns from individual decision making (Parker et al. 2008). Still, the importance of scalar dynamics in analyzing human-environment interactions is still frequently overlooked.

\subsubsection{Using Social Science Case-Studies to Help Parameterize Land Change Models}

The disconnection between the different research perspectives, and the disciplinary communities involved in the different approaches, causes land change models to neglect the knowledge gained by the narrative and empirical perspectives. A specific approach to bridge the different research approaches in land change research and generalize local findings across larger regions has been the use of meta-analysis 
of case studies. Meta-analysis is a form of systematic review aimed at the statistical evaluation of a large number of case studies and can provide the empirical base for designing simulation models. Meta-analysis is especially useful if new (and possibly more structured) data collection is not feasible due to the large time and financial investments required. Such systematic review of studies is useful in land science since globally valid explanations of what factors drive land use change remain largely incomplete (Rudel 2008). Common understanding of the causes of land change is dominated by simplifications that, in turn, underlie many land change models. Within case studies of land change, based on either the narrative or empirical research approach, a wealth of in-depth information on decision making in humanenvironment interactions is available. Meta-analysis can help to identify commonalities across these case studies and identify which factors (variables) cause different cases to behave differently. Case studies on land change often contain information on the proximate causes of land change and their underlying driving factors and provide insight in the decision making processes leading to changes in land use and management. The main approach to systematic review of the knowledge in case studies in the field of land science has been the synthesis of proximate causes and driving factors for specific land change processes resulting in a listing of the globally most frequently mentioned drivers of land change. Examples of such systematic review or meta-analysis are available for deforestation (Geist and Lambin 2002; Rudel 2005), desertification (Geist and Lambin 2004), agricultural intensification (Keys and McConnell 2005) and shifting cultivation (van Vliet et al. 2012). These meta-analysis support the conclusion that the simple answers found in population growth, poverty and infrastructure rarely provide an adequate understanding of land change. Rather, individual and social responses follow from changing economic conditions, mediated by institutional factors. Opportunities and constraints for new land uses are created by markets and policies, increasingly influenced by global factors (Lambin et al. 2001). A weakness of the existing meta-analysis in land use is that it is mainly tended towards understanding the broad, macro-scale social forces that affect nature-society relationships and less attention is given to the role of the space-time context in determining these relationships, i.e. mostly the humanenvironment system is investigated following the first conceptual model in Fig. 8.1. At the same time, the case studies included tend to be biased towards the most interesting regions with dramatic land changes.

For a more limited set of case studies Rindfuss et al. (2007) tried to more specifically identify the important factors explaining differences in land change processes between frontier regions. However, as case studies are often made by different teams and with different objectives, the quantitative comparison of such cases turned out to be more troublesome; indicating the need for more clearly documenting common sets of case study findings and harmonizing case study methods in order to be able to contextualize case study findings. Such harmonization will ensure that case study results can more easily be contextualized, allowing the use of the findings in land change models. 


\subsubsection{Representation of Human-Environment Interactions in Land Change Models}

A wide variety of land change models have been developed over the past two decades that have been reviewed numerous times (Agarwal et al. 2001; Priess and Schaldach 2008; Verburg et al. 2004b) based on different criteria. In this section we do not aim to provide an exhaustive review of these models, but rather will address the variation in ways that human-environment interactions are conceptualized in the different models. In contrast to a classification or representation based on the specific modeling technique used, e.g. cellular automata or agent-based modeling, the methods employed to represent human-environment interactions may be classified on a scale from deductive, theory-led approaches to fully empirical, inductive approaches to modeling. Overmars et al. (2007) provide such a scale from deductive to inductive reasoning and conclude that many of the existing models are neither fully deductive or inductive. But, still large differences exist in the role of theory and empirical data in conceptualizing the model. Especially the way in which decision making on land change is represented differs. In some approaches an almost completely deductive approach is taken by assuming rational agents that optimize income and tailor land change decisions towards that goal. Some of these models operate at the level of individual decision makers, e.g. farmers (Piorr et al. 2009) while others operate at the level of large world regions in which decision making is conceptualized for an aggregate (representative) agent (Havlík et al. 2011; Souty et al. 2012; Van Meijl et al. 2006). It may be questioned under what conditions the same behavioral assumptions are valid for both individual and highly aggregate agents. On the other end of the spectrum models that employ machine learning methods to relate land change to its determinants are found. Many machine learning techniques do not provide insight into the estimated relations and it is only the observed data that determine the relations employed in the model to simulate future land changes. Many other models fall somewhere in between these extremes. So called 'factor-led induction' (Overmars et al. 2007) employs theory to identify the factors driving land change decisions while the actual relations between these factors and land change are established using empirical estimation of statistical coefficients using observed data (Chomitz and Gray 1996; Nelson and Hellerstein 1997). Such a theory-based approach is important to explore for several reasons. It structures the model around the critical human-environment relationships identified within the theory, and focuses attention on the data required to explore those relationships. Similarly, many agent-based models of land change employ a range of empirical techniques to make a typology of different decision making types and parameterize the decision making rules in the model based on household survey results (Robinson et al. 2007; Smajgl et al. 2011; Valbuena et al. 2008). The latter group of models is of specific interest to the study of human-environment interactions. Multi-agent models simulate decision making by individual agents of land use change, explicitly 
addressing interactions among individuals. The explicit attention for interactions between agents makes it possible for this type of model to simulate emergent properties of systems. These are properties at the macro scale that are not predictable from observing the micro units in isolation. If the decision rules of the agents are set such that they sufficiently look like human decision making they can simulate behavior at the meso-level of social organization, i.e. the behavior of heterogeneous groups of actors. Multi-agent-based models of land change are particularly well suited to representing complex spatial interactions under heterogeneous conditions (Bousquet and Le Page 2004; Parker et al. 2003). Multi-agent systems are able to formalize decision-forming behavior of individual stakeholders, either based on theory (Happe et al. 2006), or based on observations and statistical analysis (Bousquet et al. 2001; Robinson et al. 2007; Valbuena et al. 2010a). In the initial years of application of agent-based models to land change, most multi-agent models focused on either hypothetical or simplified representations of the real world to explore interactions between agents and between agents and the environment. Especially the parameterization of agent behavior in models for real case-studies turned out to be very complex. However, more recently a larger number of applications of agent-based models to real case studies worldwide have been published, showing the potential of the approach to explore the land change dynamics in local to regional level case studies (Le et al. 2012; Robinson et al. 2012; Valbuena et al. 2010b). At larger spatial scales, ranging from the region to the global level the principles of agent-based modeling have not yet been applied in simulation models, leaving most models at that level with highly simplified representations of human-environment interactions (Rounsevell and Arneth 2011). The possibilities for either upscaling or outscaling agent-based models have been described by Rounsevell and colleagues (Rounsevell et al. 2012), but have not yet been applied in operational models.

\subsection{Land Change Models as a Platform for Social Science Integration}

The review and discussion in the previous sections has illustrated the importance of the social sciences for studying land change processes. Often, the social sciences have taken the narrative or empirical approach for studying land change. The modeling perspective is often dominated by natural scientists and in many models the social drivers of land change are underrepresented. This underrepresentation can, to some extent, be attributed to the lack of spatial data representing the social drivers. For the physical factors such data are often better available, e.g. soil maps and climate data. At the same time, the poor representation of social science in land change models is due to the difficulty to generalize social science findings outside the context of a specific case study, and the lack of an overarching theory of land change that includes the social dimensions. Still, there are several advances and prospects that allow land change models to act as a platform for social science integration in natural resource studies. 
It is not likely that the complete richness of human-environment interactions leading to land change will easily and completely be described by one single, all compassing theory that can inform the design of land change models. Different existing theories describe specific land change processes and are valid under specific conditions or at a specific scale; together the different theories help explain part of the total variation in human-environment interactions leading to land change. The combination and integration of narrative research with empirical investigations will help to better define the conditions under which certain land change processes occur and when theories and conceptual models are valid. Such understanding will help to define under what conditions land change models based on these conceptual relations can adequately capture the system dynamics. The complementary use of narrative, empirical and model-based explorations requires the interdisciplinary collaboration and exchange of insights across the different research perspectives and disciplines. Land change models may be designed based on the narrative and theoretical understanding of the human-environment interactions in a particular context. At the same time, social science perspectives may be formalized by representing them in simulation models, enabling to test the implications for system dynamics.

Besides interdisciplinary collaboration it is also required to broaden the perspective of the individual disciplinary approaches. The most effective way to reap the benefits of more deductive work is not to rigidly 'go deductive' and stay there. Such a 'process-led approach' may blind the analyst to alternative processes at work (Overmars et al. 2007). Rather, the message should be that researchers will profit most from developing a consciousness of the whole spectrum between the inductive and deductive extremes, and an awareness of the advantages of the variation in research routines, and then seeking the most fertile sequences and interactions between inductive and deductive work. Ultimately, this will contribute to theory development in the field of land change while at the same time helping the development of modeling tools to explore the dynamics in land systems and possible responses to policy interventions.

The lack of social science integration in models of land change is exemplified by the, often, very simplistic representation of human-environment interactions in operational land change models which does not do justice to the complexity of decision making. Especially at larger spatial and temporal scales models assume in most cases profit optimizing strategies at the level of either spatial units or for highly aggregate representative agents. In contrast, at local scales much advancement has been made in the representation of human behavior and decision making in agentbased models of land change. Ignoring spatial and temporal variation in decision making and responses to environmental change leads to inaccuracies in global assessment outcomes and difficulties in using these models to design place-based natural resource management and adaptation and mitigation strategies. The upscaling and/or outscaling of agent-based models of land change is restricted by the lack of empirical data to support the parameterization of the human-environment interactions in these models. Such parameterization requires insight in the diversity of diverging decision making models and the contextual conditions that may explain such diversity. To better include such social science information a promising 
direction is the re-analysis of existing case-studies and social science surveys to identify commonalities across locations as well as the role of context. The use of meta-analysis to achieve some of these objectives has revealed that information reported in case studies is often restricted and incomplete to make a full comparative analysis possible. Moreover, as narrative and econometric case studies are not conducted following a common structure or reporting protocol the necessary information to make a systematic review across case studies is often lacking in the scientific reports. Common reporting protocols to ensure that information is consistently documented have been successful in the individual-based and agentbased modeling communities. The ODD reporting protocol of individual-based and agent-based models (Grimm et al. 2006, 2010) is now common as supplementary material of all individual-based and agent-based model papers in peer-reviewed journals. A similar documentation protocol has been proposed by Seppelt and others (2012) for documenting ecosystem service assessments. If land change case-studies would apply similar documentation standards a wealth of information on land change processes and the underlying human-environment interactions worldwide would be disclosed.

Another constraint for parameterizing agent-based models is the limited information that standard land change case studies provide on the cognitive aspects of land change decisions (Meyfroidt 2012). Many studies describe the ways in which driving forces relate to land change decisions without considering the underlying cognitive processes and the way in which decision making adapts to changing conditions, including learning. While the investigation of such mechanisms is normally the field of environmental psychology, such insights are essential to understand transitions in decision making as are likely to take place under increasing influence of global markets, changing policy environments and climate change. Land change is happening in a dynamic socio-economic and environmental context, leading to dynamic decision making patterns in which we have yet insufficient insights.

Spatial simulation models are frequently used to reconstruct historic land changes (Klein Goldewijk et al. 2011) and explore future changes or evaluate the land change consequences of alternative policies. The comparison of simulation results with reality provides a measure of the extent to which we understand the humanenvironment interactions resulting in land change (Castella and Verburg 2007; Pontius et al. 2008). The wide diversity in modeling concepts and implementations serves the variation in research and policy questions as well as the different scales of analysis. Adequate land change models require the integration of social science perspectives and multi-agent models are an example of the possibility to do so. However, the challenges for better understanding and integrating human-environment interactions in land change models are still manifold. But, in the end, the development of land change models provides a platform for integrating the different disciplinary perspectives on the complex socio-ecological system governing land change. Advancing land change modeling, therefore, not only requires the efforts of individual disciplinary researchers, it especially takes the courage of all individual researchers to collaborate, contextualize findings and respond to the needs to translate findings across spatial scales. 
Acknowledgments The research leading to these results has received funding from the European Research Council under the European Union's Seventh Framework Programme (FP/2007-2013)/ ERC Grant Agreement n. 311819 and the project VOLANTE Grant Agreement n. 265104.

Open Access This chapter is distributed under the terms of the Creative Commons Attribution Noncommercial License, which permits any noncommercial use, distribution, and reproduction in any medium, provided the original author(s) and source are credited.

\section{References}

Agarwal, C., Green, G. M., Grove, J. M., Evans, T. P., \& Schweik,C. M. (2001). A review and assessment of land use change models. Dynamics of space, time, and human choice. Bloomington: Center for the Study of Institutions, Population, and Environmental Change, Indiana University; South Burlington: USDA Forest Service.

Boserup, E. (1965). The conditions of agricultural growth: The economics of agrarian change under population pressure. Chicago: Aldine.

Bousquet, F., \& Le Page, C. (2004). Multi-agent simulations and ecosystem management: A review. Ecological Modelling, 176(3-4), 313-332.

Bousquet, F., Le Page, C., Bakam, I., \& Takforyan, A. (2001). Multiagent simulations of hunting wild meat in a village in eastern Cameroon. Ecological Modelling, 139(1-3), 331-346.

Briassoulis, H. (2000). Analysis of land use change: Theoretical and modeling approaches. In S. Loveridge (Ed.), The web book of regional science. Morgantown: West Virginia University. http://rri.wvu.edu/resources/web-book-rs/

Bürgi, M., Hersperger, A. M., \& Schneeberger, N. (2004). Driving forces of landscape change Current and new directions. Landscape Ecology, 19(8), 857-868.

Castella, J. C., \& Verburg, P. H. (2007). Combination of process-oriented and pattern-oriented models of land-use change in a mountain area of Vietnam. Ecological Modelling, 202(3-4), 410-420.

Chomitz, K. M., \& Gray, D. A. (1996). Roads, land Use, and deforestation: A spatial model applied to Belize. The World Bank Economic Review, 10(3), 487-512.

Claessens, L., Schoorl, J. M., Verburg, P. H., Geraedts, L., \& Veldkamp, A. (2009). Modelling interactions and feedback mechanisms between land use change and landscape processes. Agriculture, Ecosystems and Environment, 129(1-3), 157-170.

Coleman, J. S. (1990). Foundations of social theory. Cambridge: The Belknap Press of Harvard University Press.

Easterling, W. E. (1997). Why regional studies are needed in the development of full-scale integrated assessment modelling of global change processes. Global Environmental Change Part A, 7(4), 337-356.

Fujita, M., Krugman, P., \& Mori, T. (1999a). On the evolution of hierarchical urban systems. European Economic Review, 43(2), 209-251.

Fujita, M., Krugman, P., \& Venables, A. J. (1999b). The spatial economy: Cities, regions and international trade. Cambridge, MA: MIT Press.

Geist, H. J., \& Lambin, E. F. (2002). Proximate causes and underlying driving forces of tropical deforestation. Bioscience, 52(2), 143-150.

Geist, H. J., \& Lambin, E. F. (2004). Dynamic causal patterns of desertification. Bioscience, 54(9), $817-829$.

Gibson, C. C., Ostrom, E., \& Anh, T. K. (2000). The concept of scale and the human dimensions of global change: A survey. Ecological Economics, 32(217), 239.

Grimm, V., Berger, U., Bastiansen, F., Eliassen, S., Ginot, V., Giske, J., Goss-Custard, J., Grand, T., Heinz, S. K., Huse, G., Huth, A., Jepsen, J. U., Jörgensen, C., Mooij, W. M., Müller, B., Pe'er, G., Piou, C., Railsback, S. F., Robbins, A. M., Robbins, M. M., Rossmanith, E., 
Rüger, N., Strand, E., Souissi, S., Stillman, R. A., Vabø, R., Visser, U., \& DeAngelis, D. L. (2006). A standard protocol for describing individual-based and agent-based models. Ecological Modelling, 198(1-2), 115-126.

Grimm, V., Berger, U., DeAngelis, D. L., Polhill, J. G., Giske, J., \& Railsback, S. F. (2010). The ODD protocol: A review and first update. Ecological Modelling, 221(23), 2760-2768.

Happe, K., Kellermann, K., \& Balmann, A, (2006). Agent-based analysis of agricultural policies: an illustration of the agricultural policy simulator AgriPoliS, its adaptation, and behavior. Ecology and Society, 11(1), 49. http://www.ecologyandsociety.org/vol11/iss1/art49/

Havlík, P., Schneider, U. A., Schmid, E., Böttcher, H., Fritz, S., Skalský, R., Aoki, K., Cara, S. D., Kindermann, G., Kraxner, F., Leduc, S., McCallum, I., Mosnier, A., Sauer, T., \& Obersteiner, M. (2011). Global land-use implications of first and second generation biofuel targets. Energy Policy, 39(10), 5690-5702.

Hersperger, A. M., Gennaio, M.-P., Verburg, P. H., \& Bürgi, M. (2010). Linking land change with driving forces and actors: Four conceptual models. Ecology and Society, 15(4), 1.

Hertel, T. W., Golub, A. A., Jones, A. D., O’Hare, M., Plevin, R. J., \& Kammen, D. M. (2010). Effects of US maize ethanol on global land use and greenhouse gas emissions: Estimating market-mediated responses. Bioscience, 60(3), 223-231.

James, F. C., \& McCulloch, C. E. (1990). Multivariate analysis in ecology and systematics: Panacea or Pandora's box? Annual Review of Ecology and Systematics, 21, 129-166.

Keys, E., \& McConnell, W. J. (2005). Global change and the intensification of agriculture in the tropics. Global Environmental Change Part A, 15(4), 320-337.

Klein Goldewijk, K., Beusen, A., van Drecht, G., \& de Vos, M. (2011). The HYDE 3.1 spatially explicit database of human-induced global land-use change over the past 12,000 years. Global Ecology and Biogeography, 20(1), 73-86.

Lambin, E. F., Turner, B. L., II, Geist, H. J., Agbola, S. B., Angelsen, A., Bruce, J. W., Coomes, O., Dirzo, R., Fischer, G., Folke, C., George, P. S., Homewood, K., Imbernon, J., Leemans, R., Li, X. B., Moran, E. F., Mortimore, M., Ramakrishnan, P. S., Richards, J. F., Skanes, H., Stone, G. D., Svedin, U., Veldkamp, A., Vogel, C., \& Xu, J. C. (2001). The causes of land-use and land-cover change: Moving beyond the myths. Global Environmental Change, 4, 261-269.

Lambin, E. F., Geist, H. J., \& Lepers, E. (2003). Dynamics of land-use and land-cover change in tropical regions. Annual Review of Environment and Resources, 28, 205-241.

Le, Q. B., Seidl, R., \& Scholz, R. W. (2012). Feedback loops and types of adaptation in the modelling of land-use decisions in an agent-based simulation. Environmental Modelling \& Software, 27-28, 83-96.

Liu, J., Dietz, T., Carpenter, S. R., Alberti, M., Folke, C., Moran, E., Pell, A. N., Deadman, P., Kratz, T., Lubchenco, J., Ostrom, E., Ouyang, Z., Provencher, W., Redman, C. L., Schneider, S. H., \& Taylor, W. W. (2007). Complexity of coupled human and natural systems. Science, 317(5844), 1513-1516.

Liverman, D. M., \& Cuesta, R. M. R. (2008). Human interactions with the earth system: People and pixels revisited. Earth Surface Processes and Landforms, 33(9), 1458-1471.

Marceau, D. J., \& Hay, G. J. (1999). Remote sensing contributions to the scale issue. Canadian Journal of Remote Sensing, 25(4), 357-366.

Matthews, R., Gilbert, N., Roach, A., Polhill, J., \& Gotts, N. (2007). Agent-based land-use models: a review of applications. Landscape Ecology, 22(10), 1447-1459.

Meyfroidt, P. (2012). Environmental cognitions, land change, and social-ecological feedbacks: An overview. Journal of Land Use Science, 8(3), 341-367. doi:10.1080/1747423X.2012.667452.

Nelson, G. C., \& Hellerstein, D. (1997). Do roads cause deforestation? Using satellite images in econometric analysis of land use. American Journal of Agricultural Economics, 79, 80-88.

Neumann, K., Stehfest, E., Verburg, P. H., Siebert, S., Müller, C., \& Veldkamp, A. (2011). Exploring global irrigation patterns: A multilevel modeling approach. Agricultural Systems, 104(9), 703-713.

Overmars, K. P., \& Verburg, P. H. (2005). Analysis of land use drivers at the watershed and household level: Linking two paradigms at the Philippine forest fringe. International Journal of Geographical Information Science, 19(2), 125-152. 
Overmars, K. P., \& Verburg, P. H. (2006). Multilevel modelling of land use from field to village level in the Philippines. Agricultural Systems, 89(2-3), 435-456.

Overmars, K., de Groot, W., \& Huigen, M. (2007). Comparing inductive and deductive modeling of land use decisions: Principles, a model and an illustration from the Philippines. Human Ecology, 35(4), 439-452.

Pan, W. K. Y., \& Bilsborrow, R. E. (2005). The use of a multilevel statistical model to analyze factors influencing land use: A study of the Ecuadorian Amazon. Global and Planetary Change, 47(2-4), 232-252.

Parker, D. C., \& Filatova, T. (2008). A conceptual design for a bilateral agent-based land market with heterogeneous economic agents. Computers, Environment and Urban Systems, 32(6), 454-463.

Parker, D. C., Manson, S. M., Janssen, M. A., Hoffman, M., \& Deadman, P. (2003). Multi-agent systems for the simulation of land-use and land-cover change: A review. Annals of the Association of American Geographers, 93(2), 314-337.

Parker, D. C., Hessl, A., \& Davis, S. C. (2008). Complexity, land-use modeling, and the human dimension: Fundamental challenges for mapping unknown outcome spaces. Geoforum, 39(2), 789-804.

Pfaff, A. S. P., \& Sanchez-Azofeifa, G. A. (2004). Deforestation pressure and biological reserve planning: a conceptual approach and an illustrative application for Costa Rica. Resource and Energy Economics, 26(2), 237-254.

Piorr, A., Ungaro, F., Ciancaglini, A., Happe, K., Sahrbacher, A., Sattler, C., Uthes, S., \& Zander, P. (2009). Integrated assessment of future CAP policies: Land use changes, spatial patterns and targeting. Environmental Science \& Policy, 12(8), 1122-1136.

Pontius, R., Boersma, W., Castella, J.-C., Clarke, K., de Nijs, T., Dietzel, C., Duan, Z., Fotsing, E., Goldstein, N., Kok, K., Koomen, E., Lippitt, C., McConnell, W., Mohd Sood, A., Pijanowski, B., Pithadia, S., Sweeney, S., Trung, T., Veldkamp, A., \& Verburg, P. (2008). Comparing the input, output, and validation maps for several models of land change. The Annals of Regional Science, 42, 11-37.

Priess, J. A., Schaldach, R (2008). Integrated models of the land system: A review of modelling approaches on the regional to global scale. Living Reviews in Landscape Research, 2(1). http://www.livingreviews.org/lrlr-2008-1

Rabin, M. (1998). Psychology and economics. Journal of Economic Literature, 36(1), 11-46.

Rindfuss, R. R., \& Stern, P. C. (1998). Linking remote sensing and social science: The need and the challenges. In D. Liverman, E. F. Moran, R. R. Rindfuss, \& P. C. Stern (Eds.), People and pixels: Linking remote sensing and social science (pp. 1-27). Washington, DC: National Academy Press.

Rindfuss, R. R., Walsh, S. J., Mishra, V., Fox, J., \& Dolcemascolo, G. P. (2003). Linking household and remotely sensed data, methodological and practical problems. In J. Fox, R. R. Rindfuss, S. J. Walsh, \& V. Mishra (Eds.), PEOPLE AND THE ENVIRONMENT - Approaches for linking household and community surveys to remote sensing and GIS (pp. 1-29). Boston: Kluwer Academic Publishers.

Rindfuss, R. R., Entwisle, B., Walsh, S. J., Mena, C. F., Erlien, C. M., \& Gray, C. L. (2007). Frontier land use change: Synthesis, challenges, and next steps. Annals of the Association of American Geographers, 97(4), 739-754.

Robinson, D. T., Brown, D. G., Parker, D. C., Schreinemachers, P., Janssen, M. A., Huigen, M., Wittmer, H., Gotts, N., Promburom, P., Irwin, E., Berger, T., Gatzweiler, F., \& Barnaud, C. (2007). Comparison of empirical methods for building agent-based models in land use science. Journal of Land Use Science, 2(1), 31-55.

Robinson, D. T., Murray-Rust, D., Rieser, V., Milicic, V., \& Rounsevell, M. (2012). Modelling the impacts of land system dynamics on human well-being: Using an agent-based approach to cope with data limitations in Koper, Slovenia. Computers, Environment and Urban Systems, 36(2), 164-176.

Rounsevell, M. D. A., \& Arneth, A. (2011). Representing human behaviour and decisional processes in land system models as an integral component of the earth system. Global Environmental Change, 21(3), 840-843. 
Rounsevell, M. D. A., Robinson, D. T., \& Murray-Rust, D. (2012). From actors to agents in socioecological systems models. Philosophical Transactions of the Royal Society B: Biological Sciences, 367(1586), 259-269.

Rudel, T. K. (2005). Tropical forests. Regional paths of destruction and regeneration in the late twentieth century. New York: Columbia University Press.

Rudel, T. K. (2008). Meta-analyses of case studies: A method for studying regional and global environmental change. Global Environmental Change, 18(1), 18-25.

Rudel, T. K., Schneider, L., Uriarte, M., Turner, B. L., DeFries, R., Lawrence, D., Geoghegan, J., Hecht, S., Ickowitz, A., Lambin, E. F., Birkenholtz, T., Baptista, S., \& Grau, R. (2009). Agricultural intensification and changes in cultivated areas, 1970-2005. Proceedings of the National Academy of Sciences, 106(49), 20675.

Seppelt, R., Fath, B., Burkhard, B., Fisher, J. L., Grêt-Regamey, A., Lautenbach, S., Pert, P., Hotes, S., Spangenberg, J., Verburg, P. H., \& Van Oudenhoven, A. P. E. (2012). Form follows function? Proposing a blueprint for ecosystem service assessments based on reviews and case studies. Ecological Indicators, 21, 145-154.

Smajgl, A., Brown, D. G., Valbuena, D., \& Huigen, M. G. A. (2011). Empirical characterisation of agent behaviours in socio-ecological systems. Environmental Modelling \& Software, 26(7), 837-844.

Souty, F., Brunelle, T., Dumas, P., Dorin, B., Ciais, P., Crassous, R., Müller, C., \& Bondeau, A. (2012). The nexus land-use model version 1.0, an approach articulating biophysical potentials and economic dynamics to model competition for land-use. Geoscientific Model Development, 5(1), 571-638.

Thomson, A. M., Calvin, K. V., Chini, L. P., Hurtt, G., Edmonds, J. A., Bond-Lamberty, B., Frolking, S., Wise, M. A., \& Janetos, A. C. (2010). Climate mitigation and the future of tropical landscapes. Proceedings of the National Academy of Sciences, 107(46), 19633-19638.

Turner, B. L., \& Ali, A. M. (1996). Induced intensification: Agricultural change in Bangladesh with implications for Malthus and Boserup. Proceedings of the National Academy of Sciences, 93(25), 14984-14991.

Turner, B. L., \& Fischer-Kowalski, M. (2010). Ester Boserup: An interdisciplinary visionary relevant for sustainability. Proceedings of the National Academy of Sciences, 107(51), 21963-21965.

Valbuena, D., Verburg, P. H., \& Bregt, A. K. (2008). A method to define a typology for agent-based analysis in regional land-use research. Agriculture, Ecosystems \& Environment, 128(1-2), $27-36$.

Valbuena, D., Verburg, P. H., Bregt, A. K., \& Ligtenberg, A. (2010a). An agent-based approach to model land-use change at a regional scale. Landscape Ecology, 25(2), 185-199.

Valbuena, D., Bregt, A. K., McAlpine, C., Verburg, P. H., \& Seabrook, L. (2010b). An agent-based approach to explore the effect of voluntary mechanisms on land use change: A case in rural Queensland, Australia. Journal of Environmental Management, 91(12), 2615-2625.

Van Meijl, H., van Rheenen, T., Tabeau, A., \& Eickhout, B. (2006). The impact of different policy environments on agricultural land use in Europe. Agriculture, Ecosystems \& Environment, 114(1), 21-38.

van Noordwijk, M., Lusiana, B., Villamor, G., Purnomo, H., \& Dewi, S. (2011). Feedback loops added to four conceptual models linking land change with driving forces and actors. Ecology and Society, 16(1), r1. URL: http://www.ecologyandsociety.org/vol16/iss1/resp1/

van Vliet, N., Mertz, O., Heinimann, A., Langanke, T., Pascual, U., Schmook, B., Adams, C., Schmidt-Vogt, D., Messerli, P., Leisz, S., Castella, J. C., Jörgensen, L., Birch-Thomsen, T., Hett, C., Bech-Bruun, T., Ickowitz, A., Vu, K. C., Yasuyuki, K., Fox, J., Padoch, C., Dressler, W., \& Ziegler, A. D. (2012). Trends, drivers and impacts of changes in swidden cultivation in tropical forest-agriculture frontiers: A global assessment. Global Environmental Change, 22(2), 418-429.

Veldkamp, A., Verburg, P. H., Kok, K., De Koning, G. H. J., Priess, J., \& Bergsma, A. R. (2001). The need for scale sensitive approaches in spatially explicit land use change modeling. Environmental Modeling and Assessment, 6(2), 111-121. 
Verburg, P. H. (2006). Simulating feedbacks in land use and land cover change models. Landscape Ecology, 21(8), 1171-1183.

Verburg, P. H., Ritsema van Eck, J. R., de Nijs, T. C. M., Dijst, M. J., \& Schot, P. (2004a). Determinants of land-use change patterns in the Netherlands. Environment and Planning B: Planning and Design, 31(1), 125-150.

Verburg, P. H., Schot, P. P., Dijst, M. J., \& Veldkamp, A. (2004b). Land use change modelling: Current practice and research priorities. GeoJournal, 61(4), 309-324.

Walker, R. (2004). Theorizing land-cover and land-use change: The case of tropical deforestation. International Regional Science Review, 27(3), 247-270.

Walker, R., \& Solecki, W. D. (2004). Theorizing land-cover and land-use change: The case of the Florida Everglades and its degradation. Annals of the Association of American Geographers, 94(2), 311-328.

Walsh, S. J., Evans, T. P., Welsh, W. F., Entwisle, B., \& Rindfuss, R. R. (1999). Scale-dependent relationships between population and environment in Northeastern Thailand. Photogrammetric Engineering \& Remote Sensing, 65(1), 97-105. 